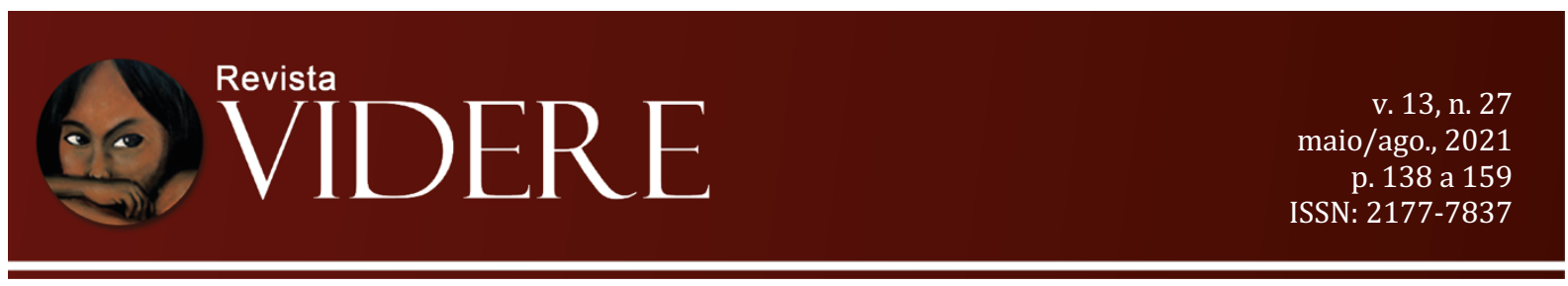

\title{
A INSERÇÃO SOCIAL DO IDOSO POR MEIO DO CONSUMO DE BENS CULTURAIS
}

\author{
THE SOCIAL INSERTION OF THE ELDERLY THROUGH THE CONSUMPTION OF \\ CULTURAL GOODS
}

\section{LA INSERCIÓN SOCIAL DE LA PERSONA MAYOR POR MEDIO DEL CONSUMO DE BIENES CULTURALES}

Tiago Cappi Janini Doutor em Direito do Estado pela Pontifícia Universidade Católica de São Paulo (PUCSP) Centro Universitári Salesiano de São Paulo (UNISAL) tiagocappi@yahoo.com.br OrcidID: https://orcid.org/0000-0001-9554-5692

\begin{abstract}
Ana Maria Viola de Sousa Doutora em Direito das Relações Sociais pela Pontifícia Universidade Católica de São Paulo (PUCSP) Centro Universitári Salesiano de São Paulo (UNISAL) violasousa.am@gmail.com OrcidID: https://orcid.org/0000-0002-2328-3643
\end{abstract}

Resumo: Este artigo objetiva identificar a hipervulnerabilidade do consumidor idoso de bens culturais e demonstrar a importância do Estado na redução dessa desigualdade. O direito à cultura, qualificado como fundamental pela Constituição de 1988 e assegurado a todos, é uma forma de inserção social do idoso. Com isso, questiona-se: Como o Estado pode contribuir efetivamente para uma maior participação do idoso na sociedade por meio do consumo de bens culturais? Para solucionar o problema, o texto tem os seguintes objetivos específicos: (i) estudar o conceito de cultura e a sua proteção jurídica; (ii) reconhecer a hipervulnerabilidade do consumidor idoso; (iii) apontar as características do consumidor idoso de bens culturais; e (iv) analisar as políticas públicas relativas ao consumo de bens culturais. Utiliza-se o método dedutivo, com pesquisa bibliográfica. Conclui-se que o Estado deve ser agir efetivamente na concretização do consumo de bens culturais pelos idosos, para minimizar a sua exclusão social.

Palavras-chave: Hiper vulnerabilidade. consumo cultural. políticas públicas culturais. acesso à cultura. idoso.

Abstract: This article aims to identify the hypervulnerability of the elderly consumer of cultural goods and demonstrate the importance of the State in reducing this inequality. The right to 
culture, qualified as fundamental by the 1988 Constitution and guaranteed to all, is a way for social insertion of the elderly. Thus, the question is: How can the State effectively contribute to a greater participation of the elderly in society through the consumption of cultural goods? To solve the problem, the text has the following specific objectives: to study the concept of culture and its legal protection; to recognize the hypervulnerability of the elderly consumer; to point out the characteristics of the elderly consumer of cultural goods; and to analyze public policies related to consumption of cultural goods. The deductive method is used, with bibliographic research. It's concluded that the State must be effectively act in the realization of the consumption of cultural goods by the elderly to minimize their social exclusion.

Keywords: Hypervulnerability. cultural consumption. cultural public policies. access to culture. elderly.

Resumen: Este artículo tiene como objetivo identificar la hipervulnerabilidad del consumidor mayor de bienes culturales y demostrar la importancia del Estado en la reducción de esta desigualdad. El derecho a la cultura, clasificado como fundamental por la Constitución de 1988 y garantizado para las personas mayores, es una forma de inserción social de los ancianos. Por lo tanto, la pregunta es: ¿Puede el Estado contribuir efectivamente para una mayor participación de los ancianos en la sociedad por medio del consumo de bienes culturales? Para resolver el problema, el texto tiene los siguientes objetivos específicos: estudiar el concepto de cultura y su protección jurídica; reconocer la hipervulnerabilidad del consumidor mayor; señalar las características del consumidor de bienes culturales de edad avanzada; y analizar las políticas públicas sobre el consumo de bienes culturales. Se utiliza el método deductivo, con investigación bibliográfica. Se concluye que el Estado debe actuar eficazmente en la realización del consumo de bienes culturales por parte de las personas mayores, con el fin de minimizar su exclusión social.

Palabras clave: Hipervulnerabilidad. consumo cultural. políticas públicas culturales. acceso a la cultura. persona mayor.

\section{Introdução}

O direito à cultura recebe status constitucional somente pela Constituição Federal de 1988 com uma sessão exclusiva, que assegura o pleno exercício dos direitos culturais, bem como o acesso às diferentes fontes de cultura. Atualmente, ganha destaque o consumo cultural pelos idosos, tendo em vista que numa sociedade envelhecida imagina-se que as pessoas idosas, por não mais se incluírem no rol dos indivíduos em idade ativa, estariam mais propensas a desfrutar melhor os seus direitos culturais. Porém, a realidade apresenta sérios desafios à concretização do direito à cultura pelos idosos.

Nesse sentido, os idosos, por serem mais vulneráveis, precisam de uma maior atenção por parte do Estado para assegurar concretamente os seus direitos fundamentais, arduamente conquistados, incluindo os direitos culturais. É sabido que o bem-estar das pessoas depende de uma série de fatores, mas no envelhecimento importa fortalecer a capacidade funcional, na qual 
se compreendem todos os atributos pessoais, físicos, psíquicos e sociais. Possibilitar o acesso à cultura para os idosos é dar-lhes dignidade, (re)conduzi-los à classe de cidadãos ativos, uma efetiva forma de inserção social.

Nas últimas décadas os idosos tiveram o reconhecimento dos seus direitos fundamentais: individuais, sociais, difusos e coletivos. Todavia, apesar dessa grande conquista, muitos desses direitos encontraram diversos obstáculos em sua concretização, tanto pela inoperância do Estado, quanto pela indiferença do cidadão com o idoso. Por isso, é necessária uma atuação efetiva por parte do Poder Público para desenvolver e implementar políticas públicas que realmente possibilitem o acesso à cultura por parte do idoso. A exclusão social do idoso está presente na sociedade, e uma das formas de (r)incluí-lo é por meio do acesso à cultura.

Este estudo tem como ponto de partida a necessidade de o Estado intervir no consumo de bens culturais pelos idosos, concretizando o seu direito fundamental à cultura. Questionase: Qual o papel do Estado para assegurar o consumo de bens culturais pelo idoso? Em outras palavras: como o Estado pode contribuir efetivamente para uma maior participação do idoso na sociedade por meio do consumo de bens culturais? A pesquisa tem por hipótese demonstrar que o Estado deve ser o principal ator na promoção de condições para que o idoso consuma bens culturais sem ser prejudicado.

Utilizando o método dedutivo e a pesquisa bibliográfica, este trabalho tem como objetivo principal identificar a condição de hipervulnerabilidade do consumidor idoso de bens culturais e demonstrar a importância do Estado na redução dessa desigualdade. Os objetivos específicos são: (i) estudar o conceito de cultura e a sua proteção jurídica; (ii) reconhecer a hipervulnerabilidade do consumidor idoso; (iii) apontar as características do consumidor idoso de bens culturais; e (iv) analisar as políticas públicas relativas ao consumo de bens culturais.

\section{A proteção jurídica da cultura}

Definir "cultura" é uma tarefa árdua. Assim como existem diversas disciplinas acadêmicas, também a expressão "cultura" adquire formas conceituais diferenciadas atinentes a cada ramo do conhecimento. Do ponto de vista da antropologia e das ciências sociais, “cultura" consiste no conjunto de padrões implícitos e explícitos de comportamentos adquiridos e transmitidos por meio de símbolos que constituem a acumulação de realizações e características de agrupamentos humanos, com suas materializações às quais se vinculam valores historicamente selecionados. (SILVA, 1986, p. 290). 
$\mathrm{Na}$ análise psicológica, dão conta de que "cultura", embora seja baseada nos comportamentos sociais, não é o próprio comportamento, mas, sim, abstrações ideais, considerando-se formas ou padrões comportamentais. Desse modo, "cultura" enfatiza recursos acumulados, materiais ou imateriais, que as pessoas em sociedade herdam, empregam, transmutam e acrescentam para transmitir à próxima geração. E, nesse sentido, há aqueles que preferem ver a "cultura" do ponto de vista histórico, já que a consideram como um "[...] complexo da hereditariedade social total da humanidade". (SILVA, 1986, p. 291).

De outro lado, Oliveira (2014, p. 18) acrescenta que etimologicamente "cultura" tem raiz na expressão latina colere (cultivar) com o significado de produção pelo trabalho. Desse modo, na concepção descritiva, utilizada pela Antropologia, é possível conceber a "cultura" como um conjunto de artefatos, objetos e instrumentos criados, utilizados ou adquiridos, bem como as crenças, ideias e valores cultivados pelos indivíduos, enquanto membros de uma sociedade. Já na concepção simbólica, incluem-se na "cultura", padrões e significados incorporados em formas simbólicas, tais como manifestações e objetos significativos, por meio dos quais os indivíduos se comunicam entre si e partilham experiências e crenças. (OLIVEIRA, 2014, p. 22). Esse autor ainda comenta haver uma dimensão materialista que conceitua "cultura" como todo modo de vida da sociedade; ou a sociológica que considera "cultura" como universo das artes, ou seja, conjunto da produção elaborada por meios específicos de expressão. (OLIVEIRA, 2014, p. 31).

Com o tempo, o termo "cultura", na análise de Ferrigno (2016, p. 343), adquiriu diversos significados, mantendo até hoje a sua característica polissêmica. Desde os dicionários, que trazem conceitos genéricos, até conceitos excêntricos e ocasionais, o fato é que todas as pessoas têm uma noção básica do que seja cultura. Ao lado das definições vulgares, a "cultura" também deve ser investigada pelas ciências.

A Constituição brasileira de 1988 estabelece um conjunto de dispositivos referentes ao direito à cultura nos arts. 215, 216 e 216-A. Juntamente com os direitos sociais e econômicos, os direitos culturais integram o rol dos direitos fundamentais, necessários ao pleno desenvolvimento das condições de uma vida digna. Embora a cultura tenha referência desde a Constituição de 1934, foi somente com a de 1988 que se estabeleceu como direitos culturais, consagrando-os como direitos fundamentais, cuja base matricial está insculpida na Declaração Universal dos Direitos Humanos, de 1948, especificamente no art. 27¹. (FERNANDES, J., 2011, p. 176).

\footnotetext{
${ }^{1}$ Declaração Universal dos Direitos Humanos (1948) art. 27: (1). Todo homem tem direito a participar livremente da vida cultural da comunidade, de fruir as artes e de participar do progresso científico e de seus benefícios. (2).
} 
Na seara jurídica, destaca-se, por oportuno, a noção de "bens culturais", que decorre do conceito de "cultura". Na análise de Alexandrino (2009), historicamente a expressão "bens culturais" apareceu a partir da II Guerra Mundial, cujos passos iniciais foram dados no âmbito do Direito Internacional e o primeiro tratado em que figura a expressão é a Convenção da UNESCO (Organização das Nações Unidas para a Educação, Ciência e Cultura) de 1954, que tem a diversidade cultural concebida como característica essencial da humanidade, razão pela qual deve ser valorizada e cultivada em benefício de todos. (OLIVEIRA, 2014, p. 40).

Na lição de Alexandrino (2009), "bem cultural” pode ser juridicamente conceituado. Nesse sentido, possui características identificando-o como um conceito indeterminado, aberto, relativo e funcional. É indeterminado porque a norma jurídica não explicita exatamente uma definição fechada, mas uma noção, à qual a doutrina costuma denominar de conceito vago; é aberto por haver uma associação com as realidades históricas que são mutáveis; é relativo porque pode dar uma definição ajustada à realidade local, variando de acordo com os interesses e categorias de bens; e é também funcional, pois serve à necessidade de sujeição de certas realidades a uma especial tutela pública, permitindo a sua fruibilidade universal.

Desse modo, juridicamente considerado, os bens culturais integram a classe de bens em geral, podendo ser móveis, imóveis, fungíveis, consumíveis, público ou privado, mas com a qualidade especial de ser "cultural" (SOUZA FILHO, 1986, p. 252). No entanto, Alexandrino (2009) alerta que os bens culturais podem ser analisados em sentido estrito, em sentido amplo e ainda em sentido impróprio. Em sentido estrito, é aquele que decorre da aplicação da lei e, nesse âmbito, são os bens de interesse arqueológico, histórico, ambiental, paisagístico, arquivístico, bibliográfico e outros que constituam um testemunho material com valor civilizatório. No sentido amplo, abrange bens imateriais que formam parcelas da identidade e da memória coletiva, os contextos dos bens materiais que com eles tenham relação informativa ou interpretativa e outros bens, desde que tutelados especificamente nas leis. Já no sentido impróprio, a expressão "bens culturais" serve para designar todas as hipóteses a que alguma norma se refira, ainda que essas realidades não integrem o elenco do "patrimônio cultural". $\mathrm{Na}$ análise de Alexandrino (2009), é nessa última modalidade que se inserem as normas constitucionais brasileiras. Como é possível observar, a própria Constituição, no caput do art. 216, adota um conceito abrangente, estabelecendo que o patrimônio cultural é formado por todos os bens de "natureza material e imaterial, tomados individual ou coletivamente,

Todo homem tem direito à proteção dos interesses morais e materiais decorrentes de qualquer produção científica, literária ou artística, da qual seja autor. 
portadores de referência à identidade, à ação, à memória dos diferentes grupos formadores da sociedade brasileira".

Com efeito, a variedade de bens culturais é imensa, pois incluem o lazer, o esporte e o turismo; as artes em geral; os patrimônios histórico, natural e paisagístico; os padrões de comportamento e manifestações que expressem a existência humana; o quadro estrutural de valores, símbolos, ideias e linguagem; os valores espirituais e filosóficos, entre outros. Tais bens culturais podem ser considerados fatores de humanização, na medida em que constituem recursos não só de entretenimento como também de aprendizagem e aquisição de conhecimentos e ainda de desenvolvimento e integração social.

No que diz respeito à natureza pública, Alexandrino (2009) argumenta que os bens culturais não se confundem com bens patrimoniais, já que estes podem ser públicos ou privados, dependendo da propriedade, enquanto aqueles, "verdadeiramente não pertencem a ninguém, considerando-se apenas público", ou seja, destinado à fruição universal. Ademais, há alguns traços fundamentais caracterizadores dos bens culturais: a imaterialidade, embora muitas vezes não se possa separar a imaterialidade do patrimonial, já que pode ou não haver suporte material; a variedade de bens; e a qualidade de natureza pública.

Esse conceito alargado de cultura justifica a importância dos chamados direitos culturais exercitáveis por toda e qualquer pessoa que integre a população. Direitos esses que podem ter dimensão passiva, como direito à fruição, por exemplo, ou dimensão ativa, como o direito à criação. (OLIVEIRA, 2014, p. 54). Essas dimensões são identificadas por Ferrigno (2016, p. 345) como consumo e produção de cultura. Nesse sentido, seriam consumidores aqueles que se apropriam ou usam dos bens culturais, enquanto os produtores, os criadores dos bens. Para José Ricardo Fernandes (2011, p. 4), nos direitos culturais incluem-se não apenas o acesso e a produção, mas também o direito à memória, no sentido de que esta representa o seu passado, tradição e história. Já Natália Fernandes (2011, p. 180), acrescenta também o direito de participação, seja em termos de tomada de decisões de política cultural, seja na de contribuição na formação do acervo cultural.

Desse modo, Oliveira (2014, p. 32) conclui que ampliar o conceito de cultura tem por objetivo abranger toda a diversidade de modos de vida e de expressões existentes na humanidade, em consonância com as premissas internacionais preconizadas pela UNESCO, as quais encontram ressonância nos diferentes dispositivos constitucionais brasileiros.

Na Constituição Federal de 1988, a referência à cultura não se esgota nos artigos 215, 216 e 216-A. Veja-se, por exemplo, o parágrafo único do art. $4^{\circ}$ (integração econômica, política, social e cultural dos povos da América latina); art. 5\%, IX (liberdade de expressão), XXVII 
(direitos autorais); art. 23, III (competência comum da União, Estados, Distrito Federal e Municípios na proteção da cultura); art. 24, VII (responsabilidade pelos danos culturais); art. 30, IX (competência municipal na proteção do patrimônio histórico-cultural); art. 210 (conteúdo mínimo do ensino fundamental para a formação de respeito aos valores culturais); art. 219 (integração do mercado interno e patrimônio nacional para o desenvolvimento socioeconômico da população); art. 221 (princípios na produção e programação das emissoras de rádio e televisão); art. 227 caput (dever da família, da sociedade e do Estado assegurar o direito à cultura); e art. 231 (cultura indígena).

Ademais, na doutrina corrente há entendimento unânime de que os direitos culturais são parte dos direitos fundamentais, pois constituem estrutura essencial da dignidade humana, cuja negação impede que o indivíduo ou coletivo de indivíduos viva com liberdade o seu processo permanente de identificação e reconhecimento. (OLIVEIRA, 2014, p. 45). No entanto, se comparado a outros direitos como os civis, políticos e econômicos, por exemplo, os direitos culturais não têm merecido o mesmo tratamento. Uma das razões, segundo Ferrigno (2016, p. 345), foi a "coisificação" da noção de cultura. Explica-se: com uma economia mercantilista houve uma prevalência do valor de troca dos produtos, de modo que o produto do trabalho humano não se valoriza pela sua capacidade de criação, mas como mercadoria que pode ser trocada por outros bens, como privilégios, prestígio e dinheiro. No entendimento de Coelho (2011, p. 8), os direitos culturais são uma "ampliação dos direitos humanos", os quais deram consistência e conteúdo à palavra liberdade. A vida cultural seria, então, um "complexo de proposições e relação que dão sentido pleno à liberdade humana".

Para que o direito à cultura seja exercido efetivamente, há a necessidade de oferta de produtos culturais de qualidade e acessíveis ao consumo adequado pela população, especialmente pelos idosos, já tão excluídos da sociedade. Todavia, importa sublinhar que não basta a simples oferta de bens culturais, deve-se respeitar a vulnerabilidade do consumidor, sobretudo o idoso.

\section{O consumidor idoso e a sua condição de hipervulnerabilidade}

A revolução tecnológica, a globalização e o fortalecimento do capitalismo são fatores que contribuíram para a massificação do consumo, transformando os comportamentos humanos. Os desequilíbrios sociais propagados pelo aparecimento da sociedade de consumo em massa reclamaram a atuação do Estado com a finalidade de reduzir a disparidade entre consumidor e fornecedor no momento da aquisição de produtos e serviços. Para isso, nas 
últimas décadas, vários países adotaram uma legislação específica com a finalidade de promover os interesses dos consumidores sobre o mercado. O Código de Defesa do Consumidor (CDC) é um exemplo de legislação preocupada em equilibrar a relação entre os agentes econômicos e os particulares, coibindo práticas abusivas e protegendo o indivíduo mais vulnerável da relação.

Para engendrar essa proteção, o CDC parte da premissa da condição de vulnerabilidade do consumidor. Com isso, reconhece uma condição de inferioridade do consumidor perante o fornecedor, requerendo regras que se preocupem em reestabelecer ou, ao menos, reduzir essa desigualdade presente na relação jurídica de consumo.

Todavia, essa condição de vulnerabilidade do consumidor pode ser agravada, resultando na hipervulnerabilidade. Explicam Pasqualotto e Soares (2017) que como o consumidor em geral é vulnerável e, por isso, está protegido pela legislação consumerista, há determinadas categorias de consumidores que estão em situação de maior potencial de risco de lesão do que aqueles em condições relativamente 'normais', podendo ser consideradas como hipervulneráveis.

Observa-se que o CDC presumiu a condição de vulnerabilidade do consumidor. Assim, pelo simples fato de ser consumidor já se enquadra como vulnerável. Sucede que, em razão de outros fatores, essa vulnerabilidade pode ser agravada, originado consumidores hipervulneráveis. Pasqualotto e Soares (2017) indicam como fatores de agravamento da vulnerabilidade do consumidor os seguintes: (i) biológicos, como a idade, a integridade física e psíquica; (ii) sociais, culturais, educacionais, técnicos e econômicos, que envolvem a condição financeira e a formação educacional; (iii) vinculados ao próprio consumo, como as circunstâncias e a época de formação do vínculo de consumo; (iv) geográfico, já que a distância entre fornecedor e consumidor interfere na relação de consumo. Advertem os autores (PASQUALOTTO; SOARES, 2017) que esses fatores podem representar a hipervulnerabilidade de forma isolada ou em conjunto.

O aumento do número de idosos e da sua melhor qualidade de vida, transformou-os em um dos principais alvos da oferta de produtos e serviços. Para isso, a tutela jurídica deve se atentar para essa classe de sujeitos, inclusive quando figuram na relação jurídica consumerista. Nesse contexto, Graeff (2013) reconhece a categoria jurídica do “consumidor idoso" em que se enquadram as pessoas com 60 anos ou mais que adquirem ou utilizam produtos e serviços como consumidoras finais.

O "consumidor idoso" consiste em uma subclasse, que integra o gênero "consumidor". O critério diferenciador é a idade, condição potencializadora da sua vulnerabilidade; torna-o 
hipervulnerável. O fator biológico da idade, para muitos consumidores, importa em uma restrição da exata compreensão da relação de consumo, principalmente em uma sociedade extremamente complexa e permeada de novas tecnologias. Embora de forma rudimentar, o CDC, no art. 39, IV, alerta para essa condição de hipervulnerabilidade do idoso ao afirmar que é "vedado ao fornecedor prevalecer-se da fraqueza ou ignorância do consumidor, tendo em vista sua idade, saúde, conhecimento ou condição social".

A condição de vulnerabilidade ampliada do consumidor idoso é defendida por Santos (2008), que explica: “[...] se há presunção de vulnerabilidade para todo e qualquer consumidor, o que se pode dizer no tocante ao consumidor idoso é que suas deficiências na relação de consumo são superiores a um indivíduo qualquer”. No mesmo sentido, Schmitt (2009) conclui existir “[...] categorias de 'hipervulneráveis', como cremos ser o caso dos consumidores idosos, os quais demandam uma proteção mais intensa, e melhor atenção do Estado para algumas formas de contratação, em que a idade se apresenta como fator de vulnerabilidade mais aguda".

É bem verdade que a análise da hipervulnerabilidade deve ser observada casuisticamente, levando-se em consideração o caso concreto. Um consumidor idoso pode ter sua vulnerabilidade potencializada em compras on line, mas não ser hipervulnerável em uma compra no supermercado. Com isso, “[...] em determinadas circunstâncias, é possível impor ao fornecedor o ônus de demonstrar que um fator indicador de uma potencial hipervulnerabilidade não ensejaria, em uma situação concreta, a inversão do ônus da prova”. (PASQUALOTTO; SOARES, 2017). Assim como a vulnerabilidade, a hipervulnerabilidade é um conceito relativo, e a sua aplicação depende do sujeito considerado e da situação concreta em que se encontra.

O idoso, ao consumir bens culturais, precisa de uma proteção especial do sistema jurídico para que não seja prejudicado nessa relação de consumo. A indústria do entretenimento é, evidentemente, o polo mais forte, tendo em vista o seu amplo poder econômico. No polo mais fraco, encontra-se o consumidor idoso, o qual enfrenta muitas dificuldades no mercado cultural, desde o alto preço até condições básicas de acessibilidade, como transporte e acomodações. Por isso, é essencial a atuação do Estado na criação de políticas públicas que ampliem e facilitem o consumo de bens culturais pelos idosos.

\section{O consumo cultural pelos idosos}

Sob o prisma da cultura, segundo Canclini (2006, p. 81-86), o consumo pode assumir uma série de características. Conceituando o consumo como "el conjunto de procesos 
socioculturales en que se realizan la apropiación y los usos de los productos", o autor discorre sobre seis modelos de consumo, que, em resumo, podem ser assim classificados:

a) Consumo como lugar de reprodução da força de trabalho e expansão do capital - visto da perspectiva da estratégia de mercado, constitui não apenas do modo como são adquiridos os produtos, mas também como conhecimento das operações em que os usuários selecionam e combinam os produtos e as mensagens, ou seja, a forma como os consumidores mesclam as estratégias dos fabricantes e as atividades necessárias para adaptá-las à dinâmica da vida cotidiana.

b) Consumo como sistema de classes e grupos que competem pela apropriação do produto social - deste ponto de vista compreende-se a existência de desigual participação na estrutura produtiva que se reflete na distribuição e apropriação dos bens, levando o consumo a uma arena de disputas de produtos.

c) Consumo como lugar de diferenciação social e distinção simbólica entre grupos - com a massificação da maioria dos bens gerada na modernidade, as diferenças se produzem cada vez mais não pelos objetos em si, mas pela forma de utilização. O consumo passa a ser uma necessidade simbólica.

d) Consumo como sistema de integração e comunicação - os modos de vida identificam as pessoas na sociedade. É na sociedade que se constrói o personagem que se deseja ser, transmitindo informações sobre si e sobre as relações que se espera estabelecer com os demais. Assim, o consumo passa a ser um jogo de intercâmbios e distinções, um sistema de comunicação.

e) Consumo como cenário de objetivação dos desejos - na verdade necessidades. Tal como as comidas satisfazem a necessidade da fome, os bens culturais satisfazem outras tantas, sejam materiais, sociais ou simbólicas.

f) Consumo como processo ritual - ao escolher, comprar e utilizar um bem, o consumidor está contribuindo para a construção de um universo de sentidos e práticas rituais. Ao satisfazer as necessidades, a aquisição dos bens está carregada de significados que ajudam a hierarquizar os atos e o configurar seu sentido.

Ao final, o autor define o consumo cultural como: "El conjunto de procesos de apropiación y usos de productos en los que el valor simbólico prevalece sobre los valores de uso y de cambio, o donde al menos estos últimos se configuran subordinados a la dimensión simbólica”. (CANCLINI, 2006, p. 89).

Quanto à população idosa, há no imaginário popular, principalmente da classe trabalhadora, de que a inatividade surge como uma promessa de um tempo de liberdade de 
escolhas. (FERRIGNO, 2016, p. 343). No entanto, as pesquisas acerca do consumo cultural pelos idosos, ainda que sejam ínfimas e pontuais, indicam que esse contingente populacional tem pouco acesso a tais bens. (FERRIGNO, 2016, p. 350; JORDÃO, 2016, p. 108; SILVA, 2016, p. 44). Para Ferrigno (2016, p. 355), a baixa participação dos idosos nos hábitos de atividades culturais decorre de uma série de fatores que vão desde a reduzida escolaridade até dificuldades econômicas, passando pela qualidade dos produtos culturais. Enfatiza, ainda, que a legislação se preocupa mais com a produção da cultura do que com o seu consumo.

De acordo com Jordão (2016, p. 105) o consumo da cultura não se estabelece de maneira igual a todos, já que se sujeita à escolha subjetiva. Além disso, as decisões dos consumidores são também influenciadas por razões relativas ao contexto e relacionadas com os produtos e serviços (JORDÃO, 2016, p. 107). Embora a pesquisa não se refira exclusivamente aos idosos, constatou-se que, dentre as variáveis pesquisadas, a grande maioria é de "não consumidores", que representou 43\%. Dentre os consumidores de "cinema" estão 33\%, consumidores de "festas", com 15\%, e praticantes culturais com 10\%. Os "não consumidores" são compostos de pessoas acima de 55 anos, casadas, com filhos, que já completaram 18 anos; têm maior concentração de pessoas aposentadas, com baixa escolaridade. Para esse grupo, as atividades que mais gostam é a prática religiosa e assistir televisão, nas quais gastam, em média, 4 horas na semana e 7 horas no final de semana. (JORDÃO, 2016, p. 108). A autora analisa que os resultados mostram que o consumo cultural ainda está longe da realidade da população brasileira em geral. Há também uma correlação significativa entre nível econômico mais elevado e maior grau de instrução com as práticas culturais. Assim, conclui a autora, não é o tempo livre que determina o consumo da cultura. (JORDÃO, 2016, p. 112).

Pesquisa realizada em Salvador, na Bahia, com amostra composta por pessoas praticantes de pilates, frequentadores de cultos religiosos, das faculdades de terceira idade, associados do Lions Clube Internacional, além de pessoas indicadas pelos próprios entrevistados, buscou saber o comportamento dos idosos no consumo de entretenimento. (PINHEIRO, 2017). Essa pesquisa concluiu que os entretenimentos mais apreciados pelos idosos é assistir televisão, seguido de ir a restaurantes e de "navegar" pela internet. (PINHEIRO, 2017, p. 98). Esses resultados são semelhantes aos encontrados pelas pesquisas realizadas por Jordão (2016) e por Mattoso, Lima e Neves (2011, p. 57).

Luana Silva (2016, p. 46) acredita que o desinteresse está associado a outras variáveis, já que a adesão, frequência e acesso às atividades não são garantidos apenas pela oferta de produtos. Existem barreiras geográficas, financeiras, sociais, psicológicas, físicas, emocionais e o grau de autonomia que também interferem nas escolhas. Igualmente é necessário levar em 
consideração o repertório cultural, o grau de envolvimento ao longo da vida, a disposição para experimentar vivências novas, a disponibilidade financeira, o nível educacional, as barreiras de comunicação e informação das instituições e até mesmo a falta de segurança. (SILVA, 2016, p., 46). Por isso, diz Luana Silva (2016, p., 47) que as atividades internas de lazer na própria residência proporcionam não só facilidades como maior segurança, apesar de os eventos externos oferecerem atendimento prioritário, vagas especiais para estacionamento, gratuidade nos transportes públicos e redução no preço dos ingressos.

Estudos e pesquisas têm demonstrado que atividades de lazer e entretenimento são importantes aliados para manter o bem-estar no envelhecimento. (MARCELLINO, 2008; MELO, 2010; MOTTA, 2006). Segundo Ferrigno (2016, p. 348), o lazer é visto como entretenimento, mas também pode ser considerado instrumento de educação. Nesse sentido, a Federação do Comércio do Rio de Janeiro concluiu que, em 2010, os brasileiros estavam lendo mais do que no ano anterior. Já entre os idosos a porcentagem de aumento foi substancial. (FERRIGNO, 2016, p, 349). O lazer ainda tem relação direta com o papel dos relacionamentos nas atividades sendo uma oportunidade para fazer parte do grupo, tendo a ver também com emoção alegria, diversão e momentos agradáveis. (PINTO; PEREIRA, 2015, p. 19-24). Na análise de Mattoso, Lima e Neves (2011, p. 2), o lazer pode objetivar três funções básicas: descanso, como reparador dos desgastes físicos e nervosos; divertimento, recreação e entretenimento, como momento de relaxamento e fuga dos problemas do dia-a-dia; e desenvolvimento da personalidade, influenciando o emocional, o psicológico e a cognição.

Também como forma de lazer, o esporte e a atividade física são cada vez mais procurados para a prática pelos idosos, pois, além de serem prazerosos, são também um meio de promover a saúde (FERRIGNO, 2016, p. 151).

Outro segmento muito buscado dentro do lazer é o do turismo, que tem crescido nos últimos tempos, principalmente visando os idosos. Há certa fragmentação do setor, criando-se, por exemplo, o turismo de lazer, de negócios, de eventos, ecoturismo, turismo religioso, rural, turismo de um dia etc. (GOMES; PINHEIRO; LACERDA, 2011, p. 21). Cavaco (2008, p. 37) argumenta que na Europa o turismo tem se segmentado para incluir os idosos como diferenciador desse serviço. No ano 2000 , esse segmento representou $11 \%$, esperando-se $13 \%$ para 2025. (CAVACO, 2008, p. 38).

Ao se falar de turismo há uma errônea interpretação de associá-lo às viagens. No entanto, Gomes Pinheiro e Lacerda (2010, p. 19) argumentam que o turismo tem a ver com o “deslocamento de um local a outro" e não necessariamente viagem na acepção da palavra, mas que represente uma permanência fora do domicílio caracterizada pela temporalidade de ação. 
Assim, pode-se promover turismo na própria cidade. Conhecer a cidade onde vive, sob o enfoque de turista possibilita uma maior valorização da pessoa em relação ao seu domicílio, além de ser acessível a várias pessoas, do ponto de vista financeiro. Infelizmente, dizem esses autores (GOMES; PINHEIRO; LACERDA, 2010, p. 21), o turismo no Brasil ainda está muito atrelado à conotação econômica, pois a sua exploração ainda é uma atividade privada. Assim, será necessário pensar as vivências de lazer no âmbito do turismo, para além dos moldes tradicionais, implicando um sentido sociocultural, de forma a despertar a percepção das pessoas para que descubram novas paisagens, sons, sabores, cheiros, sensações e ideias. (GOMES; PINHEIRO; LACERDA, 2010, p. 24).

Como acentua Lima (2010, p. 23), o turismo propõe o reconhecimento de bens culturais, atributos arquitetônicos e paisagísticos, a historicidade qualificada como patrimônio, inserindo tais bens na história e nas redes de valor cultural, numa interpretação sociocultural que provoca curiosidade, redescobrindo sua história e lendas, valorizando a atração do produto. Esse segmento, dirigido aos idosos ocasiona satisfação e bem-estar, afetos positivos e ajustamento pessoal (LIMA, 2010, p. 75), fatores indicativos de realização e bom funcionamento psicológico.

O turismo entre os idosos vem ganhando importância, constituindo fator de desenvolvimento integral da pessoa e instrumento de integração social, pois evita a retração de contatos sociais, incrementa relações de solidariedade, representa maior liberdade e independência como um dos meios de acesso à cultura.

$\mathrm{Na}$ análise de Ferrigno (2016, p. 354), fatores que indicam que os idosos buscam mais acesso à cultura são os aumentos da consciência coletiva sobre a importância e o direito à fruição dos bens culturais e seus benefícios; o crescente interesse de grupos econômicos e industriais pela clientela de idosos; e a expansão de atendimento diferenciado às pessoas de idade nas organizações públicas e privadas.

O consumo cultural de boa qualidade pode propiciar ao idoso a sua (re)colocação à categoria de cidadão, oportunizando-o a ocupação fértil do seu tempo livre e não o deixando marginalizado na sociedade. Todavia, ainda há muitas barreiras para que os idosos possam efetivamente usufruir do seu direito à cultura. Será necessário maior esforço para atender melhor às demandas e entender os anseios e interesses dos idosos, além de desenvolver ferramentas capazes de despertar interesse, criar estratégias de sensibilização e adotar posturas compatíveis com a garantia dos direitos universais de fruição da cultura. (SILVA, 2016, p. 47).

Nas últimas décadas os idosos tiveram o reconhecimento dos seus direitos fundamentais: individuais, sociais, difusos e coletivos. Todavia, apesar dessa grande conquista, 
os direitos das pessoas idosas “[...] encontram óbices para a sua garantia, tanto pela inoperância do Estado, quanto pela indiferença do cidadão com o idoso que, associadas, tornam as ações plásticas e incapazes de dar visibilidade”. (BARUFFI; SILVA, 2015, p. 104).

Desse modo, o Estado precisa desenvolver políticas públicas que garantam efetivamente aos idosos a fruição dos seus direitos, para que não se tornem apenas tinta no papel. Dentre esses direitos, inclui-se o direito à cultura, implementando soluções para que os idosos consumam os bens culturais sem prejuízos, respeitada a sua condição de hipervulnerabilidade.

\section{Políticas públicas e o consumo da cultura pelos idosos}

Em relação ao envelhecimento, a Organização Mundial da Saúde, desde 2015, vem enfatizando que as políticas públicas devem priorizar o envelhecimento saudável, entendendoo como "processo de fomentar e manter a capacidade funcional que permita o bem-estar na velhice" (OMS, 2015). É sabido que o bem-estar das pessoas depende de uma série de fatores, porém o mais importante no envelhecimento é fortalecer a capacidade funcional, na qual se compreendem todos os atributos pessoais, físicos, psíquicos e sociais. Ainda de acordo com a OMS (2015), a capacidade intrínseca, relacionada com o físico e o mental, modifica-se conforme avança a idade, perdendo muito das habilidades funcionais, pois essa capacidade mantém-se com alto nível, em média, até aos 60 anos. De outro lado, a capacidade de interação com o meio externo representa o indivíduo social no contexto das realizações que busca sua integração na comunidade e o exercício de sua cidadania, não sendo afetada pela idade. Mas o fato é que, qualquer redução das capacidades afeta consideravelmente o bem-estar dos idosos, podendo ser considerada até mesmo como um fator de risco de hipervulnerabilidade, como se procurou demonstrar acima.

Apesar de inúmeros avanços registrados no sistema jurídico nacional positivando e garantindo diversos direitos fundamentais aos idosos, o cotidiano ainda mostra um cenário desafiador. Analisando as produções científicas e os documentos oficiais sobre as políticas públicas para as pessoas idosas no Brasil, Andrade et. al. (2013) reconhecem a existência de um abismo entre a lei e a realidade dos idosos no Brasil e que só haverá uma sociedade ética com a valorização do potencial dos idosos com a sua cidadania garantida. Por isso, imperiosa a maior participação do Estado na concretização dos direitos fundamentais dos idosos, sobretudo na cultura, através das políticas públicas. 
Políticas públicas culturais são os instrumentos que asseguram a promoção e a proteção dos direitos culturais e podem ser entendidas como o conjunto de princípios operacionais, práticas administrativas e orçamentárias e procedimentos que fornecem uma base para a ação cultural do Estado. Assim, o Estado é o sujeito ativo principal e o responsável prioritário na elaboração e execução das políticas públicas com a participação da sociedade civil. (OLIVEIRA, 2014, p. 67). Não só por essas duas entidades, mas também por outras tantas, como órgãos, conselhos e fundos que devem trabalhar de forma integrada e democrática, e que constituem elementos de coordenação, articulação e deliberação, instrumentos de gestão e sistemas setoriais de cultura, conforme se observa do art. 216-A da Constituição Federal.

O crescimento da cultura requer extrema participação do Estado na implementação de políticas de apoio à sua produção, evitando-se as exigências do mercado e possibilitando o seu consumo. A cultura não é um bem de fácil mercantilização e o seu desenvolvimento, muitas vezes, depende do apoio estatal. A cultura é, portanto, uma parcela fundamental da sociedade que merece atenção do Estado como uma das áreas de grande importância em suas políticas públicas. (FERNANDES; OLIVEIRA, 2016).

A gestão cultural no Brasil no âmbito do Ministério da Cultura é realizada pelo Sistema Nacional de Cultura ${ }^{2}$, que congrega diversas legislações, seguindo orientação descentralizada e participativa como modelo de gestão compartilhada que objetiva garantir a existência e a continuidade das políticas para concretização dos direitos culturais. (OLIVEIRA, 2014, p. 114). Integram esse sistema:

- Lei 12.343, de 2 de dezembro de 2010, que instituiu o Plano Nacional de Cultura, dispondo sobre planejamento e implementação de políticas públicas relacionadas à proteção e promoção da diversidade cultural brasileira. Sua previsão de incremento é de dez anos, abrangendo três dimensões: a cultura como expressão simbólica, a cultura como direito de cidadania e a cultura como potencial de desenvolvimento econômico. (SILVA, 2016, p. 48).

- Lei 13.018, de 22 de julho de 2014, que dispõe sobre a Política Nacional da Cultura Viva. Esta lei permite promover apoio aos diversos pontos de cultura espalhados pelo Brasil, especialmente grupos da periferia dos grandes centros urbanos. As organizações comunitárias são selecionadas, mediante edital público para credenciamento, autorizando transferência financeira direta. Ao estabelecer esta parceria o Estado objetiva dar visibilidade aos grupos culturais, potencializando iniciativas culturais já desenvolvidas pelas comunidades. (OLIVEIRA, 2014, p. 87).

\footnotetext{
${ }^{2}$ O Sistema Nacional de Cultura, como é organizado hoje, foi proposto pela Emenda Constitucional $\mathrm{n}^{\mathrm{o}} 71$, de 2012, que introduziu o art. 216-A na Constituição Federal de 1988.
} 
- Lei 12.761, de 27 de dezembro de 2012, que institui o programa de cultura do trabalhador, denominado vale-cultura. Trata-se de Programa de Cultura do Trabalhador, destinado a fornecer aos trabalhadores meios para o exercício dos direitos culturais e acesso às fontes da cultura.

- Lei 8.313, de 23 de dezembro de $1991^{3}$, conhecida como Lei Rouanet, que trata de investimentos a projetos culturais, através do Fundo Nacional de Cultura e concessão de renúncia fiscal.

Ainda no âmbito da pessoa idosa, necessário citar também a Lei 10.098, de 19 de dezembro de 2000, bem como a NBR 9050, da Associação Brasileira de Normas Técnicas, que dispõe sobre a eliminação, redução ou superação de barreiras, garante condições seguras de acesso, trânsito, orientação e comunicação, facilitando a utilização de tais bens, observados os critérios e parâmetros na construção, instalação e adaptação de edificações. Há também a Portaria 41, de 12 de setembro de 2007, do Ministério da Cultura que estabelece o Programa de Fomento e valorização das Expressões Culturais da Pessoa Idosa, como incentivo ao enfrentamento de preconceito contra idosos.

Silva (2017, p. 167) comenta que, apesar de as leis indicarem gestão descentralizada, os projetos contemplados pelos editais públicos, concentram grupos que trabalham nos grandes centros urbanos, principalmente São Paulo e Rio de Janeiro. Até mesmo os indicadores formulados pelo Observatório Itaú $\mathrm{Cultural}^{4}$, que apresentam recentes melhoras no índice cultural, demonstrando um desenvolvimento da cultura, não atingem os objetivos propostos pelas políticas públicas. $\mathrm{O}$ fomento à política para os projetos menores, realizados no interior das cidades brasileiras ainda não chegou. Para que as políticas públicas alcancem o seu objetivo e permita que todas as pessoas, sejam idosas ou não, possam ter acesso à cultura, Silva (2017, p. 176) propõe a implantação de microações culturais no interior das cidades brasileiras. Justifica que, apesar de as indústrias do interior brasileiro serem menores, elas existem e

\footnotetext{
${ }^{3}$ Atualmente está em vigor a Instrução Normativa no 2, de 23 de abril de 2019, que estabelece procedimentos para apresentação, recebimento, análise, homologação, execução, acompanhamento, prestação de contas e avaliação de resultados de projetos culturais financiados por meio do mecanismo de Incentivo Fiscal do Programa Nacional de Apoio à Cultura.

${ }^{4}$ O Observatório Itaú Cultural foi criado em 2006 com foco na gestão, na economia e nas políticas culturais. O programa visa estudar e debater esses temas, estimular a reflexão sobre eles em seus vários aspectos e analisar os indicadores nacionais. O Observatório realiza seminários, encontros e palestras entre especialistas de todo o mundo; apoia e estimula a produção de estudos acadêmicos voltados para temas relacionados à gestão cultural, por meio do Rumos Pesquisa; possui uma linha editorial responsável pela publicação de livros e da Revista Observatório, disponível gratuitamente para consulta e download no site; promove pesquisas; e organiza informações sobre o campo cultural. Desde 2009, o programa realiza um curso de especialização em gestão cultural em parceria com a Cátedra Unesco de Políticas Culturais, a Cooperação da Universidade de Girona, Espanha, e com o apoio da Organização dos Estados Ibero-Americanos (OEI). O curso é gratuito, tem duração de um ano letivo e se estrutura por meio de aulas presenciais e virtuais.
} 
exercem o seu papel. Se tais entidades forem conectadas à indústria da cultura, em parceria com os órgãos educacionais, certamente as propostas constitucionais de uma cidadania cultural poderão ser efetivadas.

Segundo Natália Fernandes (2011, p. 178-179) a política pública como forma de atuação do Estado em relação à cultura pode ser expressa em duas tendências: cultura com relação ao mercado e cultura como cidadania. A cultura relacionada ao mercado determina ao Estado sua posição de mediador das relações entre produtores culturais, empresas ou pessoas físicas interessadas em financiar projetos culturais e que serão beneficiadas com incentivos. Já a cultura como expressão da cidadania, o Estado tem o dever de garantir o direito do cidadão de acesso e produção das diversas formas de cultura, respeitando o trabalho de criação, bem como proteger todo o patrimônio cultural.

Com isso, observa-se que o Estado ${ }^{5}$ deve ser o ator principal na inclusão do idoso no consumo de bens culturais, implementando políticas públicas que ampliem a oferta de produtos culturais com acessibilidade financeira e física aos idosos. O Estatuto do Idoso ${ }^{6}$, por exemplo, assegura descontos em atividades de cultura, esporte e lazer. Porém, ainda é uma atuação muito tímida. Há que se reduzir distâncias e melhorar o transporte para viabilizar a chegada aos cinemas, teatros, centros de lazer etc. Com isso, uma empresa que promova um espetáculo cultural precisa garantir o fácil acesso aos idosos, criando condições suficientes tais como: acentos específicos, informações detalhadas, condições de acessibilidade, preço promocional.

Deve-se, portanto, possibilitar ao idoso o consumo de bens culturais, porém em condição de igualdade com os fornecedores, em razão de sua hipervulnerabilidade. $\mathrm{O}$ acesso à cultura pelo idoso demanda políticas públicas que respeitem sua condição de parte mais fraca na relação jurídica consumerística, estimulando a sua participação. Garantir o direito à cultura para os idosos é uma forma de inclusão, promovendo sua independência e inserção social. Necessita-se, para isso, de um Estado preocupado e atuante em promover a dignidade aos idosos.

\section{Conclusões}

\footnotetext{
${ }^{5} \mathrm{O}$ art. $3^{\circ}$ do Estatuto do Idoso (Lei n. 10.741/03) aduz ser obrigação do Poder Público, ao lado da família, da comunidade, da sociedade, assegurar ao idoso, com absoluta prioridade, a efetivação do direito à vida, à saúde, à alimentação, à educação, à cultura, ao esporte, ao lazer, ao trabalho, à cidadania, à liberdade, à dignidade, ao respeito e à convivência familiar e comunitária.

${ }^{6}$ Art. 23. A participação dos idosos em atividades culturais e de lazer será proporcionada mediante descontos de pelo menos $50 \%$ (cinquenta por cento) nos ingressos para eventos artísticos, culturais, esportivos e de lazer, bem como o acesso preferencial aos respectivos locais.
} 
O direito à cultura é um dos direitos fundamentais que tem recebido menor atenção por parte do Poder Público, mas é visto como essencial componente de identidade e de cidadania, fazendo parte constitutiva da dignidade humana. Ainda que a Constituição Federal de 1988 estabeleça a garantia do pleno exercício dos direitos culturais, e, especificamente em relação ao idoso, haja diferentes disposições no Estatuto do Idoso, Lei n. 10.741/2003, sobre esses direitos, a verdade é que estudos de diferentes modalidades concluem que este contingente populacional ainda não participa efetivamente do acesso à cultura.

Muitos idosos não foram educados para o exercício da cultura. Na maioria das vezes, viveram boa parte de suas vidas apenas para o trabalho de subsistência e não tinham condições financeiras que os direcionassem a tais atividades. Embora a cultura seja reconhecida como elemento essencial para uma vida saudável, há diversas barreiras a serem ultrapassadas para a concretização desses direitos.

A cultura, evidentemente, ante a característica da diversidade, engloba, desde a leitura, o lazer, o entretenimento, o turismo, o folclore, as histórias, as atividades físicas, o patrimônio material ou imaterial, as artes em geral, entre outros. Popularmente imagina-se que sua fruição depende do tempo disponível. Contudo, as pesquisas revelaram que o tempo livre não é determinante para o exercício desse direito; o seu acesso e fruição depende principalmente de decisões pessoais, dos hábitos comportamentais, das influências do contexto, das razões do produto ou serviço cultural oferecido.

O consumo da cultura, como qualquer outro objeto de consumo não ocorre de maneira igual para todos. Para que o consumo cultural alcance os objetivos entre os idosos, tais como, promoção da saúde afetiva, realização do potencial humano, potencialização do funcionamento psicológico e manutenção da capacidade funcional, é necessária a efetiva atuação do Estado como idealizador de políticas públicas que assegurem condições suficientes para o consumo de bens culturais pelos idosos, reconhecendo a sua condição de hipervulnerabilidade.

Se o consumo cultural depende de decisão pessoal, as políticas públicas devem incentivar o desenvolvimento de ferramentas que sejam capazes de despertar o interesse, sensibilizando os idosos ao seu acesso. Do mesmo modo, se o acesso à cultura depende do contexto e das razões do produto oferecido, há que se ter políticas que garantam não apenas a facilidade de ingresso ao local, mas também as condições de segurança e de preço justo; quanto aos produtos devem ser acessíveis às condições do idoso, de boa qualidade, que atendam às necessidades específicas e propiciem diferentes opções para obter o melhor aproveitamento, elegendo a liberdade como atributo da dignidade dos idosos. 
Assim, entende-se que o Estado deve ser um efetivo ator na promoção da concretização do consumo de bens culturais pelos idosos, como forma de minimizar a sua exclusão social. Não basta garantir o acesso à cultura e desenvolver políticas públicas direcionadas aos idosos, é preciso uma atuação concreta, incentivando e fomentando o fornecimento de bens culturais destinados à população idosa.

\section{Referências}

ALEXANDRINO, José de Melo. O conceito de bem cultural. Aula proferida em 3 de dezembro de 2009, no curso de direito do Instituto de Ciências Jurídico-Políticas da Universidade de Lisboa/Portugal. Disponível em http://icjp.pt/sites/default/files/media/565466.pdf Acesso em 30 out 2019.

ANDRADE, Luana Machado et al. Políticas públicas para pessoas idosas no Brasil: uma revisão integrativa. Ciência \& saúde coletiva, Rio de Janeiro, v. 18, n. 12, p. 3543-3552, dez. 2013. Disponível em: http://www.scielo.br/scielo.php?script=sci arttext\&pid=S141381232013001200011\&lng=en\&nrm=iso. Acesso em: 31 mar. 2020.

BARUFFI, Helder; SILVA, Débora dos Santos. A dignidade humana e a proteção à pessoa do idoso: práticas sociais. Revista Videre, v. 6, n. 12, p. 93-106, dez. 2015. Disponível em: http://ojs.ufgd.edu.br/index.php/videre/article/view/4311. Acesso em: 28 mar. 2020.

CANCLINI, Néstor García. El consumo cultural: una propuesta teórica. In: SUNKEL, Guillermo (Coord.) El consumo cultural en America Latina - construcción teórica y líneas de investigación. Bogotá (Colômbia): Convenio AndresBello, 2006.

CAVACO, Carminda. Turismo sénior: perfis e práticas. Cogitur - Journal of Tourism Studies, Lisboa, v. 2, n. 2, p. 33-64, 2009. Disponível em: https://revistas.ulusofona.pt/index.php/jts/article/view/515. Acesso em: 31 out. 2019.

FERNANDES, José Ricardo Oriá. O direito à memória: análise dos princípios constitucionais da política de patrimônio cultural no Brasil (1988-2010). II Seminário Internacional de Políticas Culturais, realizado de 21 a 23 de setembro de 2011, pela Fundação Casa Rui Barbosa, Rio de Janeiro. Anais... Disponível em: http://www.casaruibarbosa.gov.br/dados/DOC/palestras/Politicas_Culturais/II_Seminario_Int ernacional/FCRB JoseRicardoFernandes_O direito_a memoria.pdf. Acesso em: 30 out. 2019.

FERNANDES, Natalia Morato. A cultura como direito: reflexões acerca da cidadania cultural. Semina: Ciências Sociais e Humanas, Londrina, v. 32, n. 2, p. 171-180, jul.-dez. 2011. Disponível em: http://www.uel.br/revistas/uel/index.php/seminasoc/article/view/13256. Acesso em: 30 out. 2019.

FERNANDES, Fabiana Constância; OLIVEIRA, Rafael Niebuhr Maia de. O financiamento estatal à cultura no Brasil: a Lei Rouanet, suas mazelas e as propostas do projeto de lei 6.722/10. Revista Direito \& Paz, Lorena/SP, v. 1, n. 34, p. 99-120, jan.-jun. 2016. 
Disponível em: http://www.revista.unisal.br/lo/index.php/direitoepaz/article/view/266/247. Acesso em: 27 mar. 2020.

FERRIGNO, José Carlos. O cidadão idoso: consumidor e produtor cultural. In:

ALCÂNTARA, Alexandre de Oliveira: CAMARANO, Ana Amélia; GIACOMIN, Karla Cristina. (Orgs.). Política Nacional do idoso: velhas e novas questões. Rio de Janeiro: Ipea, 2016. Disponível em: http://repositorio.ipea.gov.br/handle/11058/9127 Acesso em: 30 out. 2019.

GOMES, Christiane; PINHEIRO, Marcos; LACERDA; Leonardo. Lazer, turismo e inclusão social - intervenção com idosos. Belo Horizonte: Editora UFMG, 2010.

GRAEFF, Bibiana. Direitos do consumidor idoso no Brasil. Revista de Direito do Consumidor, São Paulo, v. 86, p. 65-74, mar.-abr., 2013. Disponível em: https://www.revistadostribunais.com.br/maf/app/resultList/document?\&src=rl\&srguid=i0ad6a dc600000171235f4f98a6b72ce5\&docguid=Id43a9510a71f11e2979c010000000000\&hitguid=

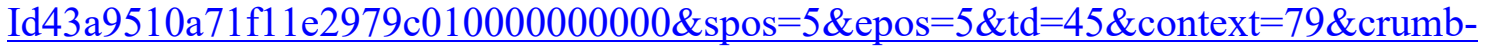
action=append\&crumb-

label=Documento\&isDocFG $=$ false\&isFromMultiSumm $=$ \&startChunk=1\&endChunk $=1$ \#note DTR.2013.3087-n2. Acesso em: 28 mar. 2020.

JORDÃO, Gisele. Comportamento de consumo artístico brasileiro. Revista do Centro de Pesquisa e formação, São Paulo, n. 2, p. 104-113, maio 2016. Disponível em: https://www.sescsp.org.br/online/artigo/10231_GISELE+JORDAO. Acesso em: 26 mar. 2020.

LIMA, Lívia Morais Garcia. Turismo, cultura e velhice bem-sucedida: contribuições para a elaboração de atividades turístico culturais para idosos no contexto das fazendas históricas paulistas. Dissertação [Mestrado em Gerontologia]. Universidade Estadual de Campinas, SP, 2010 .

MARCELLINO, N. C. Políticas de lazer: mercadores ou educadores? Os cínicos bobos da corte. In: MARCELLINO, N. C. (Org.). Políticas públicas de lazer. Campinas: Alínea, 2008.

MATTOSO, Cecília Lima de Queiros; LIMA, Aline da Silva; NEVES, Laís da Silva. Influência das classes sociais no consumo de lazer entre idosos e jovens. Revista ADM.MADE, Rio de Janeiro, ano 11, v. 15, n. 2, p. 9-62, maio.-set. 2011. Disponível em: http://revistaadmmade.estacio.br/index.php/admmade/article/viewFile/162/126. Acesso em: 26 mar. 2020.

MELO, V. A. Contribuições da História para o estudo do lazer. In: MELO, V. A. (Org.) Lazer: olhares multidisciplinares. Rio de Janeiro: Alinea, 2010.

MOTTA, A. B. Visão antropológica do envelhecimento. In: FREITAS, E. V., et. al.. Tratado de Geriatria e Gerontologia. 2 ed. Rio de Janeiro: Guanabara Koogan, 2006.

OLIVEIRA, Danilo Junior de. Direitos culturais e políticas públicas: os marcos normativos do sistema nacional de cultura. Tese de Doutorado em Direito. Universidade de São Paulo. São Paulo: USP, 2014. 162f. 
ORGANIZAÇÃO Mundial da Saúde (OMS). Informe mundial sobre el envejecimiento y la salud. USA: Organização Mundial da Saúde, 2015. Disponível em www.who.int/ageing/publications/world-report-2015/es/Acesso em 4 mai. 2017.

PASQUALOTTO, Adalberto; SOARES, Flaviana Rampazzo. Consumidor hipervulnerável: análise crítica, substrato axiológico, contornos e abrangência. Revista de Direito do Consumidor, São Paulo, v. 113, p. 81-109, set.-out., 2017. Disponível em:

https://www.revistadostribunais.com.br/maf/app/resultList/document?\&src=rl\&srguid=i0ad6a dc600000171238ce681d4a2b306\&docguid =Ibbccfc40a98411e7a46f010000000000\&hitguid= Ibbccfc40a98411e7a46f010000000000\&spos $=4 \&$ epos $=4 \& \mathrm{td}=4 \&$ context $=197 \&$ crumbaction $=$ append\&crumb-

label=Documento\&isDocFG=false\&isFromMultiSumm=\&startChunk=1\&endChunk=1. Acesso em: 28 mar. 2020.

PINHEIRO, Taluhama Guimarães Rosário. O comportamento dos consumidores idosos no consumo de entretenimento antes e após a aposentadoria: uma abordagem do paradigma do lifecourse. Dissertação [Mestrado em Administração]. UNIFACs - Universidade de Salvador, 2017. $296 f$.

PINTO, Marcelo de Rezende: PEREIRA, Danielle Ramos de Miranda. Investigando o consumo de lazer por idosos. PODIUM - Sport, Leisure and Tourism Review, São Paulo, v. 4, n.1, p. 15-32, jan.-abr. 2015. Disponível em: Acesso em: 22 mar. 2020.

SANTOS, Fabíola Meira de Almeida. Reflexões acerca do consumidor-idoso e a necessidade de efetivação dos direitos desta categoria especial de indivíduos. Revista de Direito Privado, São Paulo, v. 36, p. 119-140, out.-dez., 2008. Disponível em:

https://www.revistadostribunais.com.br/maf/app/resultList/document?\&src=rl\&srguid=i0ad82 d9a0000017131709e84c3270144\&docguid=I1c017870f25311dfab6f010000000000\&hitguid $=\mathrm{I} 1 \mathrm{c} 017870 \mathrm{f} 25311 \mathrm{dfab} 6 \mathrm{f} 010000000000 \&$ spos $=31 \&$ epos $=31 \& \mathrm{td}=45 \&$ context $=21 \& \mathrm{crumb}-$ action=append\&crumb-

label=Documento\&isDocFG $=$ false\&isFromMultiSumm $=\&$ startChunk $=1 \&$ endChunk $=1$ \#note DTR.2008.607-n3. Acesso em: 30 mar. 2020.

SCHMITT, Cristiano Heineck. A "hipervulnerabilidade" do consumidor idoso. Revista de Direito do Consumidor, São Paulo, v. 70, p. 139-171, abr.-jun., 2009. Disponível em: https:/www.revistadostribunais.com.br/maf/app/resultList/document?\&src=rl\&srguid=i0ad82 d9a0000017131709e84c3270144\&docguid=I01d86350f25311dfab6f010000000000\&hitguid $=\mathrm{I} 01 \mathrm{~d} 86350 \mathrm{f} 25311 \mathrm{dfab} 6 \mathrm{f} 010000000000 \&$ spos $=43 \&$ epos $=43 \& \mathrm{td}=45 \&$ context $=21 \& \mathrm{crumb}-$ action=append\&crumblabel=Documento\&isDocFG=false\&isFromMultiSumm=\&startChunk=1\&endChunk=1. Acesso em: 30 mar. 2020.

SILVA, Alessandro Antônio da. Política cultural no Brasil: do plano nacional de cultura às (micro) ações descentralizadas. Tese [Doutorado em Comunicação e Semiótica]. Pontifícia Universidade Católica de São Paulo. São Paulo: PUC, 2017. $276 f$.

SILVA, Benedicto. Dicionário de ciências sociais. Rio de Janeiro: Editora Fundação Getúlio Vargas, 1986. 
SILVA, Luana Gonçalves Viera da. Públicos idosos e museus no Brasil: formas de atuação e perspectivas - estudo exploratório. Dissertação de Mestrado em Museologia. Universidade de São Paulo. São Paulo, 2016. 169f.

SOUZA FILHO, Carlos Frederico Mares de. A Tutela dos Bens Culturais e a

Responsabilidade Patrimonial do Estado. Revista da Faculdade de Direito UFPR, Curitiba, v. 23, p. 247-267, dez. 1986. Disponível em:

https://revistas.ufpr.br/direito/article/view/8923/6232. Acesso em: 03 fev. 2020.

Data de recebimento: 03.06.2021

Data de aprovação: 02.07.2021 